Bangladesh Journal of Bioethics 2020; 11 (3): 43-48

\title{
Ethics after Darwin: Completing the Revolution
}

\section{Rainer Ebert}

PhD. Visiting Research Fellow

Centre de recherche en éthique

2910 Boulevard Édouard-Montpetit

Montréal, QC H3T 1J7, Canada

Email: rainerebert@gmail.com Web: www.rainerebert.com

DOI: https://doi.org/10.3329/bioethics.v11i3.51221

Abstract: This is a big-picture discussion of an important implication of Darwinism for ethics. I argue that there is a misfit between our scientific view of the natural world and the view, still dominant in academic philosophy and wider society alike, that there is a discrete hierarchy of moral status among conscious beings. I will suggest that the clear line of traditional morality - between human beings and other animals - is a remnant of an obsolete moral outlook, not least because it has no counterpart in empirical reality, and I will invite the reader to think, with me, about tenable alternatives.

Keywords: evolution, speciesism, human dignity, moral status, moral equality

Introduction: There is a great deal of disagreement about matters of morality across social, cultural, and religious boundaries. And yet, there are some moral beliefs that are shared by a great majority of people in most societies and cultures, and across religious traditions. One such belief, perhaps the most consequential of all, is the belief that there is something morally special about being human. The fact that someone is a human being, rather than a dog or a cow or a rat, is thought to make a big difference in how he or she may be treated. People of faith sometimes say that human lives, and human lives only, are sacred, as humans, and humans only, are created in the image and likeness of God. ${ }^{1}$ The German philosopher Immanuel Kant expressed a similar idea in secular terms. $\mathrm{He}$ argued that humans, but no other animals, have an intrinsic worth - "dignity" - which makes them valuable "above all price." ${ }^{2}$ In stark contrast, he held that nonhuman animals are valuable only insofar as they are useful in advancing human interests. They "exist only as means, and not for their own sakes [...], whereas man is the end." 3 This type of thinking defines much of our current relationship with nonhuman animals, and has grave practical implications. If human life is priceless, humans may not be killed, even if doing so would promote the greater good, whereas other animals, having a much lesser moral status, can be sacrificed for minor and sometimes even the most trivial human pleasures. In particular, people generally believe that we are justified in killing nonhuman animals simply because we prefer the taste of their bodies over plant-based alternatives, yet would be horrified at the idea of killing an innocent human being for the same purpose, or even if necessary to achieve something as important as saving the lives of other humans.

For convenience of expression, I will subsume under the term "traditional 
morality" a spectrum of diverse moral worldviews that have the idea of equal human worth or dignity at their core, and I will sketch an evolutionary argument that casts serious doubt on all of them. I will focus on the big picture, at the expense of some of the rigor that is ordinarily expected from a philosophy paper. My hope is to spark your curiosity, enough to read my lengthier publications in which I develop the argument in more detail.

Discussion: If all humans are to count the same, and more than other animals, that must be true in virtue of some feature that all humans have in common, but other animals lack. A philosophical defense of traditional morality must identify that feature. An obvious candidate, of course, is species membership. We are all biologically humans, members of the species Homo sapiens, and other animals are not. If we in fact deserve special treatment, could that be the reason why?

James Rachels calls the view that grounds our full moral status in the fact that we are members of the human species "unqualified speciesism." According to unqualified speciesism, "mere species alone is morally important. [...] [T]he bare fact that an individual is a member of a certain species, unsupplemented by any other consideration, is enough to make a difference in how that individual should be treated." "As quickly as our membership in the human species comes to mind as a candidate for the ground of our supposed superiority, as implausible it seems after just a moment's reflection.

Imagine we came across a hitherto undiscovered species on a remote island in the Pacific. The members of that species are intelligent. They have institutions of government and learning very much like we do, and rich emotional and cultural lives. They have been aware of our existence for a while, and they have studied our societies and languages from afar, but they chose not to reveal themselves, seeking to avoid possible conflict. We can converse about science and philosophy with them, and agree with them to engage in joint projects. Surely, if one of us were to injure or kill one of them for a small personal gain, as we do in the case of non-human animals without much thought or hesitation, the rest of us would be morally outraged - and rightly so. Just because they belong to a species that is not our own does not make it acceptable to treat them as if they were less than us. Otherwise, how could we credibly object to someone who treats people of different races or the opposite sex as inferior? There is no reason to believe that species membership, in itself, is more relevant to morality than race or sex, which is why unqualified speciesism is deeply implausible and philosophers who defend it are few and far between.

A much more promising variety of speciesism is qualified speciesism. "On this view, species alone is not regarded as morally significant. However, speciesmembership is correlated with other differences that are significant." Within qualified speciesism, I think it is helpful to distinguish between views that are committed to moral individualism and views that instead appeal to kind membership. Views of the first sort hold that there is an intrinsic feature, typically a potential or genetic disposition for some specific kind of mental life, that is necessary for membership in the human species and at the same time sufficient for 
full moral status. ${ }^{6}$ In contrast, views of the second sort hold that, rather than each having an intrinsic feature that confers full moral status, humans are special because they belong to a kind that is characterized by the fact that its members normally, albeit not universally, have certain intrinsic features, such as the advanced cognitive capacities we have in common with the intelligent beings on the newly-discovered Pacific island in our thought experiment. ${ }^{7}$

Traditional morality, regardless of which of these two forms of qualified speciesism it takes, fits well with the Aristotelian idea of a hierarchy of being, according to which each species is a static group of organisms with a distinct essence. The philosophical line of traditional morality that morally distinguishes humans from other animals finds its match in the empirical line that Aristotle thought distinguishes the human species from other animal species. ${ }^{8}$ Since the publication of Charles Darwin's The Origin of Species in 1859, however, we know that there is no such line on the empirical side of things. ${ }^{9}$ We now understand that all life is interrelated, and that biological characteristics come in degree and continually evolve as a result of natural selection. That is particularly true for the psychological capacities that are commonly associated with the special moral status of human beings, such as autonomy, rationality, self-consciousness, language ability, and moral agency. As the principle of evolutionary continuity informs us, any differences between species are differences in degree, and not in kind, and I will argue that this change in scientific perspective has important moral implications.
Before presenting my argument, however, I should make a disclaimer. In the decades after the publication of The Origin of Species, there was considerable debate over what, if anything, Darwinism can tell us about issues in moral philosophy, and much of that debate has to do with the old philosophical question of the relation between fact and value, the so-called $i s$ ought problem. Henry Sidgwick wrote in 1876 that the theory of evolution "has little or no bearing upon ethics," 10 and Ludwig Wittgenstein similarly remarked in the 1920s that the "Darwinian theory has no more to do with philosophy than has any other hypothesis of natural science." 11 In a sense, they are right. The connection between Darwinism and moral philosophy is more subtle than straightforward logical implication. What I will argue then, to put it more carefully, is that Darwinism undermines traditional morality, chipping away at its credibility, rather than outright disproving it. That being said, let us get back to our comparison between the Aristotelian and the Darwinian perspective on nature.

Darwin has replaced the Aristotelian picture of life on earth as an assortment of neatly separated boxes, one for each species, with what we now know to be the real picture, that of a vast and complex tree of life, with branches so numerous that most are likely still unknown to us. According to traditional morality, only a small number of the individuals represented in that tree, $u s$, have a special moral status, and constitute the community of moral equals, from which all non-human life is excluded. If that is to be true, we should be able to draw a line between $u s$ and them. But where should we draw that line? There is no recognizable discontinuity in the 
spectra of degrees of capacity, potential, or genetic disposition for the psychological capacities that are commonly associated with the special moral status of humans. Being autonomous, rational, selfconscious, able to use language, and so on all are scalar properties - i.e., they come in degrees -, which makes line-drawing problematic, for at least two reasons.

First, wherever we choose to draw the line, our choice will be arbitrary, at least to some degree. For the moral individualist, who as we recall ties full moral status to having the potential or genetic disposition for a certain degree of mental capacity, drawing the line is tantamount to specifying that degree, and how could there be a principled reason to pick one degree over another that is only slightly different from it? The qualified speciesist arguing from kind membership too must specify a degree of mental capacity that must be normal for a kind in order for the members of that kind to qualify for full moral status, and he or she must further explain what it takes for a capacity to become the norm for a given kind. Again, there seems to be no principled way to do that.

Second, even if we somehow find a nonarbitrary way to draw the line, doing so implausibly opens a moral gulf between individuals whose difference from one another in terms of empirical reality is entirely unremarkable. Wherever we cut through the tree of evolution, those facing each other along the cut will be strikingly similar in their bodily and mental nature, yet traditional morality would have us treat them in fundamentally different ways.

To further illustrate my argument, I am borrowing a thought experiment from
English evolutionary biologist Richard Dawkins:

Imagine you take "a picture of yourself. Now take a picture of your father and place it on top. Then find a picture of his father, your grandfather. Then place on top of that a picture of your grandfather's father, your great-grandfather. [...] Now do the same thing with his father, your great-greatgrandfather. And just carry on piling the pictures on top of each other, going back through more and more and more great-great-greats. [...] How many greats do we need for our thought experiment? Oh, a mere 185 million or so will do nicely! [...] It isn't easy to imagine a pile of 185 million pictures. How high would it be? Well, if each picture was printed as a normal picture postcard, 185 million pictures would form a tower about 220,000 feet high: that's more than 180 New York skyscrapers standing on top of each other. [...] What did [your 185-million-greatsgrandfather] look like? An old man with wispy hair and white sidewhiskers? A caveman in a leopard skin? Forget any such thought. [...] Your 185-million-greatsgrandfather was a fish. So was your 185-million-greats-grandmother, which is just as well or they couldn't have mated with each other and you wouldn't be here."12

If traditional morality is to be believed and there is to be a community of moral equals, one of your great-great-greats must have been the first to be a member of that 
community. Let us call him Adam. Which picture in the pile shows Adam? It is hard to tell! In fact, there seems to be no principled way to determine who among your ancestors was Adam. Note that this is not an innocuous case of vagueness, as in the case of the concept of baldness, but a serious shortcoming, as much depends, in terms of morality, on where we draw the line that separates equals from unequals. It makes a great difference in the way your $(\text { great })^{\mathrm{n}+1}$-grandfather would have deserved to be treated whether we decide that he is Adam, or instead decide that your (great) ${ }^{\mathrm{n}}$ grandfather gets to be Adam, and yet there seems to be no more or less reason to go one way rather than the other. For example, who among the two gets to be Adam matters greatly for the morality of killing them. It is much more seriously wrong to kill someone with full moral status than it is to kill someone with a lesser moral status, and it is implausible, and moreover morally unacceptable, that there could be individuals for whom it depends on an arbitrary, unprincipled choice whether they are entitled to the protection enjoyed by moral equals.

Further, whichever picture we pick, the intrinsic difference between the individual on that picture, Adam, and his father will be unnoticeable. If the two of them were to stand in front of us today, we would most likely not be able to tell who among them is more similar to us in terms of autonomy, rationality, self-consciousness, language ability, and all the other capacities we commonly associate with our heightened moral status. In stark contrast to whatever minor differences in biological reality there may be, the way traditional morality would have us treat Adam, who has full moral status, is radically different from the way it would have us treat his father, who does not have full moral status. That is implausible. It is implausible that a small difference in genetics or capacity makes a momentous difference in terms of moral status.

Conclusion: What can we take away from all this? We have seen that there is a tension between the biological fact that all life is interrelated, through evolution, and biological characteristics come in degree and the philosophical idea of a discrete hierarchy of moral status. Consequently, traditional morality seems to be in serious trouble. It simply does not fit our modern scientific view of the natural world. The line posited by traditional morality, between humans and other animals, turns out to be a remnant of an obsolete moral outlook, with no counterpart in empirical reality. As I see it, there are two ways we can go from here. We can abandon the idea that there is a special class of morally considerable beings who have an equal moral status higher than that of all others, and instead endorse some sort of consequentialism, or perhaps a deontological moral theory that accommodates gradual moral status. Or we can attempt to find an alternative basis for full and equal moral status, which would have to be a non-threshold property that is both binary and ethically relevant, hence allowing us to carve out of the natural world of organisms the community of moral equals along a non-arbitrary line that carries empirical significance. If you, like me, believe that human equality is a great achievement that we should not give up easily, I hope you will agree that it is well worth to try to go the second way. In my doctoral dissertation ${ }^{13}$ and recent papers in Social Theory and Practice ${ }^{14}$ and Philosophia, ${ }^{15} \mathrm{I}$ hint at an alternative to 
traditional morality that upholds the ideal of equality, and provide a more detailed version of the argument sketched in this article. In a nutshell, I argue that phenomenal consciousness, a deeply mysterious phenomenon that scientists and philosophers have hardly begun to understand, might have occurred in evolution from one generation of animals to the next, and hence can serve as a plausible and non-arbitrary cut-off point - separating "someones" from "somethings." If the community of moral equals in fact coincides with the community of conscious beings, the implications for our way of life would be far-reaching. Most importantly, we would be under a moral obligation to

\section{References}

${ }^{1}$ Cf., for example, Richard Harries, Norman Solomon \& Timothy Winter, Abraham's Children: Jews, Christians and Muslims in Conversation (London/New York: T\&T Clark, 2006), Part II, Chapter 5.

${ }^{2}$ Immanuel Kant, Groundwork of the Metaphysics of Morals, transl. and ed. by Mary Gregor (Cambridge: Cambridge University Press, 1997), p. 42, 4:434.

${ }^{3}$ Immanuel Kant, Lectures on Ethics, ed. by P. Heath \& J. B. Schneewind, transl. by P. Heath (Cambridge: Cambridge University Press, 1997), p. 212, 27:458-459.

${ }^{4}$ James Rachels, Created from Animals: The Moral Implications of Darwinism (Oxford: Oxford University Press, 1990), p. 183.

${ }^{5}$ Rachels 1990, p. 184.

${ }^{6}$ For recent examples of such views, see Massimo Reichlin, "The Argument from Potential: A Reappraisal," Bioethics 11 (1997), pp. 1-23, Patrick Lee \& Robert P. George, "The Nature and Basis of Human Dignity," Ratio Juris 21 (2008), pp. 173-193, and S. Matthew Liao, "The Basis of Human Moral Status," Journal of Moral Philosophy 7 (2010), pp. 159-179.

${ }^{7}$ Examples are Carl Cohen, "The Case for the Use of Animals in Biomedical Research," New England Journal of Medicine 315 (1986), pp. 865-870, and Michael Allen Fox, The Case for Animal Experimentation: An Evolutionary and Ethical Perspective (Berkeley: University of California Press, 1986). move away from consuming conscious animals and towards a plant-based diet.

Acknowledgments: I would like to thank François Jaquet, C. E. Abbate, and audiences at Lagos State University, the Twentieth Asian Bioethics Conference in Bangladesh, the University of Nairobi, the University of Dar es Salaam, Jagannath University, and Rice University for helpful feedback on various versions of this paper.

Author contribution: The author developed the conceptual idea and wrote the manuscript.

Conflict of interest: The author declares no conflict of interest.

${ }^{8}$ Cf. Marc Ereshefsky, "Species," The Stanford Encyclopedia of Philosophy (Fall 2017 Edition), ed. by Edward N. Zalta, URL = $<$ https://plato.stanford.edu/archives/fall2017/ent ries/species/>.

${ }^{9}$ A line from a later book by Darwin usefully illustrates the departure from Aristotle's claim that humans are separate in kind from other animals in virtue of their rationality, and is often quoted in the animal ethics literature: "the difference in mind between man and the higher animals, great as it is, certainly is one of degree and not of kind" (Charles Darwin, The Descent of Man, Part One (New York: American Home Library, 1902), p. 170).

${ }^{10}$ Henry Sidgwick, Essays on Ethics and Method (Oxford: Oxford University Press, 2000), p. 11.

${ }^{11}$ Ludwig Wittgenstein, Tractatus LogicoPhilosophicus (New York: Harcourt, Brace, and Company, 1922), p. 77, 4.1122.

12 Richard Dawkins, The Illustrated Magic of Reality (New York: Free Press, 2012), pp. 3840.

${ }^{13}$ Rainer Ebert, "The Wrongness of Killing," $P h D$ dissertation, Rice University (2016), URL = $<$ http://hdl.handle.net/1911/96270>.

${ }^{14}$ Rainer Ebert, "Mental-Threshold Egalitarianism: How not to ground full moral status," Social Theory and Practice 44 (2018), pp. 75-93.

${ }^{15}$ Rainer Ebert, “Are Humans More Equal Than Other Animals? An Evolutionary Argument Against Exclusively Human Dignity," Philosophia 48 (2020), pp. 1807-1823. 